\title{
Experimental Investigations of EDM Parameters with Graphite Electrode on Copper Tungsten using Taguchi Method
}

\author{
Apiwat Muttamara $^{1}$ and Chairath Tantipaibulvut ${ }^{1}$ \\ ${ }^{1}$ Faculty of Engineering, Thammasat University, Phatumthani, Thailand
}

\begin{abstract}
Electrical discharge machining (EDM) is a machining method primarily used for hard metals which are difficult to machine with traditional techniques. This research is to evaluate the best parameter to spark copper tungsten workpiece with graphite electrode by applying Taguchi method. This experiment can be considered and analyzed the optimal machine parameter as following: Duty factor, On-time, Discharge current, and Open load voltage with consideration of Material Removal Rate (MRR), Electrode Wear Ratio (EWR) and Surface Roughness (SR). As the experiment result, the optimization of all factors for MRR can be seen as following: Duty factor is $20 \%$, On-time is $17.6 \mu$ s, current is 15 ampere, Open-voltage is 260 volt and the optimization of all factors for EWR can be seen as following: Duty factor at $20 \%$, ON time at 17.6 $\mu$, discharge current at $15 \mathrm{~A}$ and open load voltage $80 \mathrm{~V}$.
\end{abstract}

Keywords: Electrical discharge machining, EDM, Taguchi, optimization

\section{Introduction}

Electrical Discharge Machining (EDM) is a machine that is used as non-traditional manufacturing. Furthermore EDM can operate as surface finish in last stage of tool production. Copper tungsten $(\mathrm{CuW})$ is an important tool and die material mainly because of its high electrical conductivity, and wear resistance. Due to its properties, it cannot be processed easily by EDM with normal copper electrode. So EDM process will open up an opportunity for the machining of hard materials. Graphite is produced with a wide range of material characteristics in order to allow matching the electrode material properties to the EDM applications[1]. On the other hand, fabricating for graphite is much easier than a copper. In an EDM operation, it is need to select right parameters for sparking performance. However, the right and desired parameters that base on the experience, instruction manual or a large number of test of experiment that require a lot of time and materials. Therefore, a comprehensive study of the effects of EDM parameters (peak current, machining voltage, pulse duration and interval time) on the machining characteristics such as electrode wear rate, material removal rate, surface roughness, is of great significance and could be of necessity. The Taguchi method, which is a powerful tool for parametric design of performance characteristics, is used to determine the optimal machining parameters for minimum electrode wear ratio, maximum material removal rate and minimum surface roughness in the EDM operations [2-4]. The experimental details when using the Taguchi method are described.

\section{Background}

The Taguchi method is a technique that provides an efficient methodology for process optimisation. It has been widely used for process optimisation. This is due to the advantages of the design of experiment using Taguchi's technique, which includes simplification of experimental plan and feasibility of study of interaction between different parameters. Shahul Backer et.al investigated the optimization of MRR and EWR on EDM by Using Taguchi's Method and ANOVA. The process parameters such as peak current, pulse on time and pulse off time were optimized with EDM for OHNS EN-31[5]. Rajmohan T. investigated the optimization of Machining Parameters in Electrical Discharge Machining (EDM) of 304 Stainless Steel[6]. The work are carried out as per design of experiment approach using L9 orthogonal array. The results are analyzed using ANOVA and response graphs. From this study, it is found that different combinations of EDM process parameters are required to achieve higher MRR for 304SS. Regardless of category of the performance characteristics, a greater S/N ratio 
value corresponds to a better performance. The optimal value of machining parameters is the level with the greatest $\mathrm{S} / \mathrm{N}$ ratio value. Lesser number of experiments is required in this method. As a consequence, time as well as cost is reduced considerably. Taguchi proposes experimental plan in terms of orthogonal array that gives different combinations of parameters and their levels for each experiment. According to this technique, the entire parameter space is studied with minimal number of necessary experiments only [7,8]. Based on the average output value of the quality characteristic at each parameter level, main effect analysis is performed. Analysis of variance (ANOVA) is then used to determine which process parameter is statistically significant and the contribution of each process

\section{Experimental Procedure}

Copper Tungsten $(\mathrm{Cu}-70 \%$ and $\mathrm{W}-30 \%)$ alloy was the target material used in this experiment. Table 1 shows the electrode material related properties. Experiments were performed using a MITSUBISHI: Electrical Discharge Machine, Series EA8. A cylinder of pure graphite (EDM-3) with a diameter of $3 \mathrm{~mm}$ was used as an electrode. Kerosene was used as the dielectric fluid in this experiment.

TABLE I: Electrode specification

\begin{tabular}{lc}
\hline \hline Average Particle Size $(\mu \mathrm{m})$ & $<5$ \\
\hline Flexural Strength (psi) & 13,300 \\
Compressive Strength (psi) & 18,100 \\
Hardness (shore) & 73 \\
Electrical Resistivity ( $\mu$ Ohm-in) & 615 \\
\hline \hline
\end{tabular}

Source: POCO's EDM-3 [9]

\subsection{Design of Experiments}

The experimental layout for the machining parameters using the L9 orthogonal array was used in this study. This array consists of four control parameters and three level, as shown in table 3. In the taguchi method, most all of the observed values are calculated based on 'the higher the better' and 'the smaller the better'. Thus in this study, the observed values of MRR, EWR and SR were set to maximum, minimum and minimum respectively. Each experimental trial was performed with three simple replications at each set value. Next, the optimisation of the observed values was determined by comparing the standard analysis and analysis of variance (ANOVA) which was based on the taguchi method.

TABLE II: Design of Experiment of Parameters and Levels

\begin{tabular}{|l|c|c|c|c|}
\hline Parameters & Level 1 & Level 2 & Level 3 & Unit \\
\hline Duty Factor & 6 & 20 & 50 & $\%$ \\
\hline On Time & 4.8 & 17.6 & 64 & $\mu \mathrm{s}$ \\
\hline Discharge Current & 10 & 15 & 25 & $\mathrm{~V}$ \\
\hline Open load voltage & 80 & 150 & 260 & $\mathrm{~V}$ \\
\hline
\end{tabular}

TABLE III: Taguchi’s L9 Orthogonal Arrays

\begin{tabular}{|c|l|l|l|l|}
\hline \multirow{2}{*}{ No. } & A & B & C & D \\
\cline { 2 - 5 } & $\mathbf{D F}$ & $\mathbf{t}_{\mathbf{e}}$ & $\mathbf{I}$ & Vo. \\
\hline $\mathbf{1}$ & 1 & 1 & 1 & 1 \\
\hline $\mathbf{2}$ & 1 & 2 & 2 & 2 \\
\hline $\mathbf{3}$ & 1 & 3 & 3 & 3 \\
\hline $\mathbf{4}$ & 2 & 1 & 2 & 3 \\
\hline $\mathbf{5}$ & 2 & 2 & 3 & 1 \\
\hline $\mathbf{6}$ & 2 & 3 & 1 & 2 \\
\hline $\mathbf{7}$ & 3 & 1 & 3 & 2 \\
\hline $\mathbf{8}$ & 3 & 2 & 1 & 3 \\
\hline $\mathbf{9}$ & 3 & 3 & 2 & 1 \\
\hline
\end{tabular}




\section{Results and Discussions}

The results and discussions had been focused on the effects of process parameters to the observed values (EWR, MRR and SR) based on the Taguchi methodology.

\subsection{Material Removal Rate}

As peak current increases, kinetic energy of the spark increases, leading to increase in temperature, material increases which leads to increase in MRR [10]. However, EWR may affect to MRR in the high discharge current. The MRR increases and then decreases after a certain threshold point with increase in $25 \mathrm{~A}$. Further increment in Ton leads to vaporisation of workpiece leading to rise in MRR. The MRR decreases with increase in open load voltage, and then increases after a certain threshold point with increase in 150 to $260 \mathrm{~V}$. Fig. 1(d). As open load voltage increases, the rate of voltage induce increasing of current. The optimal machining condition to obtain maximum MRR was found to be $\mathrm{I}=15 \mathrm{~A}$, Ton $=17.6 \mu \mathrm{s} . \mathrm{DF}=20 \%$ and voltage $=260 \mathrm{~V}$.

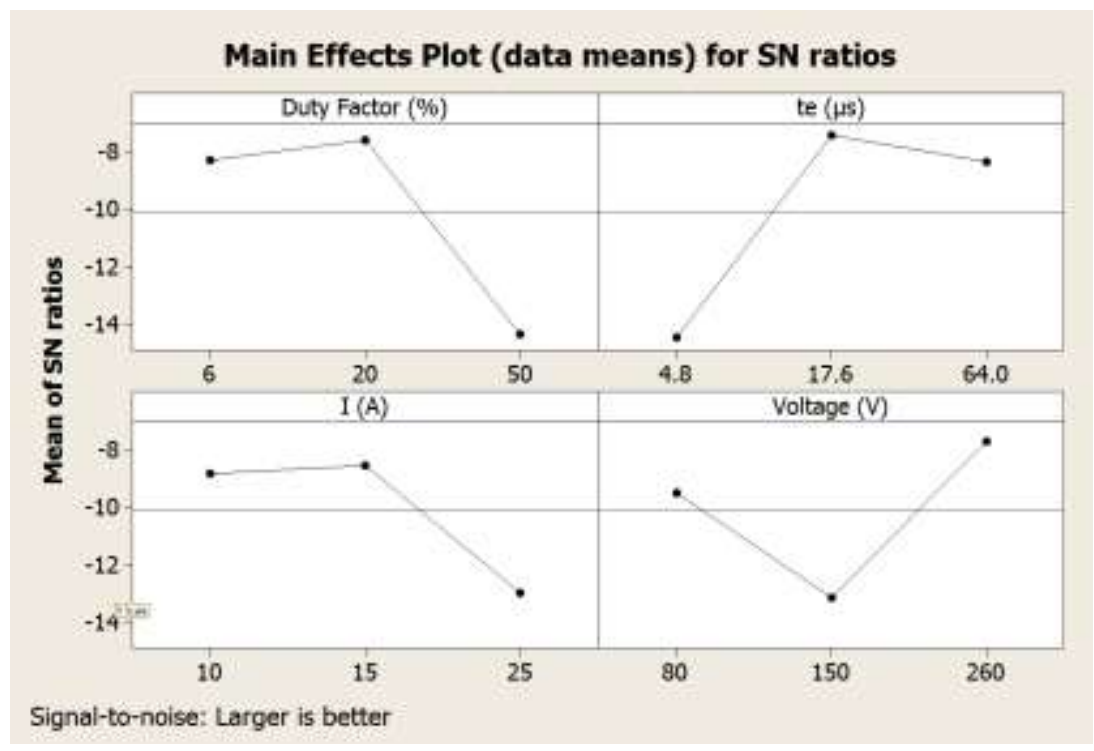

Fig. 1: Main effects for $\mathrm{S} / \mathrm{N}$ ratio of each factor on MRR

TABLE IV: Response Table for Signal to Noise Ratios (MRR)

(Larger is better)

\begin{tabular}{|l|c|c|c|c|}
\hline Level & D.F(\%) & te $(\mu \mathrm{s})$ & $\mathrm{I}(\mathrm{A})$ & $($ Voltage V) \\
\hline $\mathbf{1}$ & -8.253 & -14.452 & -8.758 & -9.444 \\
\hline $\mathbf{2}$ & -7.566 & -7.403 & -8.481 & -13.097 \\
\hline $\mathbf{3}$ & -14.354 & -8.318 & -12.934 & -7.632 \\
\hline Delta & 6.789 & 7.049 & 4.452 & 5.465 \\
\hline Rank & 2 & 1 & 4 & 3 \\
\hline
\end{tabular}

\subsection{Electrode Wear Rate}

Fig. 2 shows the main effects of EWR of each factor for various level conditions. According to figure 2, the EWR decreases with the two major parameters, D.F and Voltage. And also we notice that minimum machining voltage (negative polarity), maximum peak current, minimum pulse duration and maximum interval time may imply a smaller EWR. Thus, according to I Puertas and C.J.Luis etc.[10], discharge current, discharge voltage are the important machining parameters affecting the electrode wear ratio. The EWR increases and is due to rise in temperature causes electrode wear [11]. The optimal machining condition to obtain minimum EWR is found to be $\mathrm{I}=15 \mathrm{~A}$, Ton $=17.6 \mu \mathrm{s}, \mathrm{DF}=20 \%$ and open load voltage $=80 \mathrm{~V}$. 
TABLE V: Response Table for Signal to Noise Ratios (EWR)

(Smaller is better)

\begin{tabular}{|l|c|c|c|c|}
\hline Level & D.F $(\%)$ & te $(\mu \mathrm{s})$ & I $(\mathrm{A})$ & $($ Voltage V) \\
\hline $\mathbf{1}$ & -49.62 & -50.91 & -53.12 & -47.12 \\
\hline $\mathbf{2}$ & -46.74 & -48.84 & -49.12 & -55.95 \\
\hline $\mathbf{3}$ & -58.05 & -54.65 & -52.16 & -51.33 \\
\hline Delta & 11.31 & 5.81 & 4.00 & 8.83 \\
\hline Rank & 1 & 3 & 4 & 2 \\
\hline
\end{tabular}

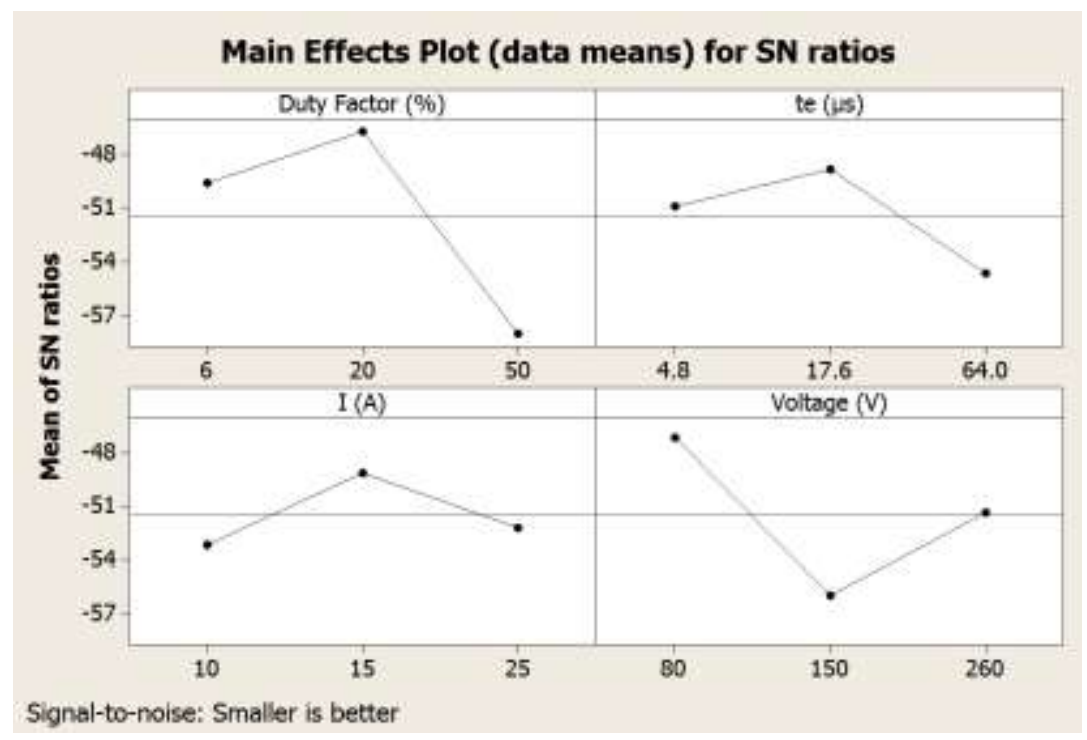

Fig. 2: Main effects for $\mathrm{S} / \mathrm{N}$ ratio of each factor on EWR

\subsection{Surface Roughness}

The main effects of surface roughness of each factor for various level conditions are shown in Fig.3. According to this figure the SR increases with voltage and slightly increases with peak current. Larger craters were produced by a larger power supply voltage, possibly producing a larger discharging energy. The influence of peak current on surface roughness is shown in Fig. 4. The surface roughness using $25 \mathrm{~A}$ of discharge current is rougher than that using $10 \mathrm{~A}$ of discharge current. The variation of crater diameter, depth and volume with respect to peak current is consistent with the general findings in EDM literature that higher currents generate larger crater and therefore produces rough surfaces. The optimal machining condition to obtain minimum surface roughness is found to be $\mathrm{I}=10 \mathrm{~A}$, Ton $=4.8 \mu \mathrm{s}, \mathrm{DF}=6 \%$ and open load voltage $=150 \mathrm{~V}$.

TABLE VI: Response Table for Signal to Noise Ratios (SR)

(Smaller is better)

\begin{tabular}{|l|l|l|l|l|}
\hline Level & D.F $(\%)$ & te $(\mu \mathrm{s})$ & I $(\mathrm{A})$ & $($ Voltage V) \\
\hline $\mathbf{1}$ & -18.60 & -19.21 & -17.85 & -20.57 \\
\hline $\mathbf{2}$ & -20.24 & -20.77 & -20.50 & -18.55 \\
\hline $\mathbf{3}$ & -20.50 & -19.35 & -20.99 & -20.22 \\
\hline Delta & 1.89 & 1.56 & 3.14 & 2.02 \\
\hline Rank & 3 & 4 & 1 & 2 \\
\hline
\end{tabular}




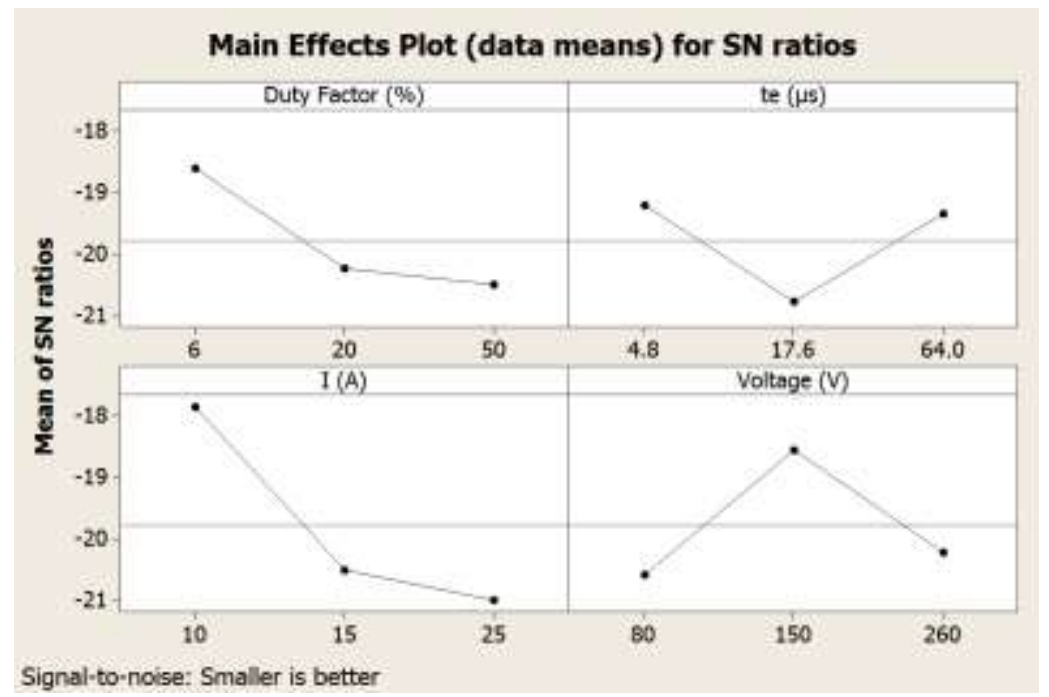

Fig. 3: Main effects for $\mathrm{S} / \mathrm{N}$ ratio of each factor on surface roughness

a) $\mathrm{I}=25 \mathrm{~A}$

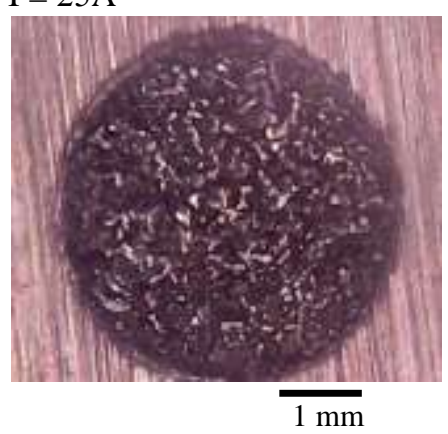

b) $\mathrm{I}=10 \mathrm{~A}$

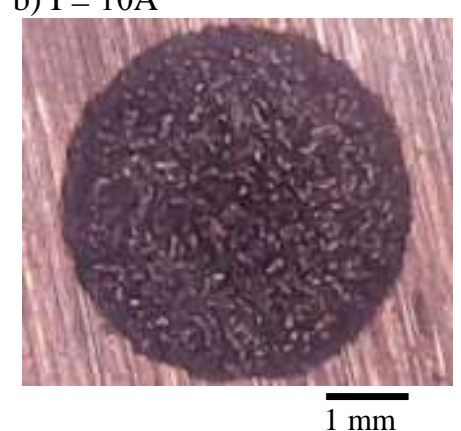

Fig. 4: Influence of peak current on EDMed surface using a) $\mathrm{I}=25 \mathrm{~A}$ and b) $\mathrm{I}=10 \mathrm{~A}$

\subsection{Confirmation test}

The confirmation test for the optimal parameters with its levels were conducted to evaluate quality characteristics for EDM. Table 7 shows the comparison of the experimental results for the optimal conditions with predicted results for optimal (A2B2C2D3) for MRR. The predicted values were obtained by estimation of MRR $=0.4487 \mathrm{~mm}^{3} / \mathrm{min}$ while as experimental result gave $0.6551 \mathrm{~mm}^{3} / \mathrm{min}$. It can be seen from this table that the difference between experimental result and the estimated result is only $0.206 \mathrm{~mm}^{3} / \mathrm{min}$.

The comparisons of the EWR according to optimal test and the predicted combination A3B3C1D2, and the experiment are given in Table 8. According to these comparisons, the differences were $4.58 \%$. This verifies that the experimental result is correlated with the estimated result. The response values obtained from the experiments are $\mathrm{MRR}=0.65 \mathrm{~mm}^{3} / \mathrm{min}, \mathrm{EWR}=100.47 \%$.

Surface roughness is $0.62 \mu \mathrm{m}$ with A3B2C3D1 which are shown in Table 9. The comparison again shows the agreement between the predicted and the experimental $0.41 \mu \mathrm{m}$.

TABLE VII : Results of Confirmation Experiment for MRR

\begin{tabular}{|c|c|c|c|}
\hline & \multirow{2}{*}{ Estimation } & Conditions & \multirow{2}{*}{ Difference } \\
\cline { 3 - 3 } & & Experiment & \\
\hline Level & $\mathrm{A}_{2} \mathrm{~B}_{2} \mathrm{C}_{2} \mathrm{D}_{3}$ & $\mathrm{~A}_{1} \mathrm{~B}_{3} \mathrm{C}_{3} \mathrm{D}_{3}$ & \\
\hline MRR & 0.6551 & 0.4487 & 0.2064 \\
\hline S/N Ratio & -2.2939 & -6.9626 & 4.6687 \\
\hline
\end{tabular}


TABLE VIII : Results of Confirmation Experiment for EWR

\begin{tabular}{|c|c|c|c|}
\hline & \multirow{2}{*}{ Estimation } & Conditions & \multirow{2}{*}{ Difference } \\
\cline { 3 - 3 } & & Experiment & \\
\hline Level & $\mathrm{A}_{3} \mathrm{~B}_{3} \mathrm{C}_{1} \mathrm{D}_{2}$ & $\mathrm{~A}_{2} \mathrm{~B}_{2} \mathrm{C}_{3} \mathrm{D}_{1}$ & \\
\hline EWR & $100.47 \%$ & $105.13 \%$ & $-4.58 \%$ \\
\hline S/N Ratio & 1.2722 & -0.4558 & -1.728 \\
\hline
\end{tabular}

TABLE IX : Results of Confirmation Experiment for Ra

\begin{tabular}{|c|c|c|c|}
\hline & \multirow{2}{*}{ Estimation } & Conditions & \multirow{2}{*}{ Difference } \\
\cline { 3 - 3 } & & Experiment & \\
\hline Level & $\mathrm{A}_{3} \mathrm{~B}_{2} \mathrm{C}_{3} \mathrm{D}_{1}$ & $\mathrm{~A}_{1} \mathrm{~B}_{1} \mathrm{C}_{1} \mathrm{D}_{1}$ & \\
\hline $\mathrm{Ra}$ & $0.62 \mu \mathrm{m}$ & $1.03 \mu \mathrm{m}$ & $-0.41 \mu \mathrm{m}$ \\
\hline S/N Ratio & 0.4239 & -0.2567 & 0.6806 \\
\hline
\end{tabular}

\section{Conclusions}

Taguchi method was applied in this study to improve the multi-response characteristics such as MRR (Material Removal Rate), EWR (Electrode Wear Rate) and surface roughness after EDM process. The conclusions of this work are summarized as follows:

- The optimal parameters combination for MRR was determined as $\mathrm{A}_{2} \mathrm{~B}_{2} \mathrm{C}_{2} \mathrm{D}_{3}$ i.e. Duty factor at $20 \%$, ON time at $17.6 \mu \mathrm{s}$, discharge current at $15 \mathrm{~A}$ and open load voltage $260 \mathrm{~V}$.

- The optimal parameters combination for EWR was determined as $\mathrm{A}_{3} \mathrm{~B}_{3} \mathrm{C}_{1} \mathrm{D}_{2}$ i.e. Duty factor at $50 \%, \mathrm{ON}$ time at $64 \mu \mathrm{s}$, discharge current at $10 \mathrm{~A}$ and open load voltage $150 \mathrm{~V}$.

- The optimal parameters combination for surface roughness was determined as $\mathrm{A}_{3} \mathrm{~B}_{2} \mathrm{C}_{3} \mathrm{D}_{1}$ i.e. Duty factor at $50 \%$, ON time at $17.6 \mu$ s, discharge current at $25 \mathrm{~A}$ and open load voltage $80 \mathrm{~V}$.

\section{Acknowledgements}

The authors gratefully acknowledge the financial support provided by National Research Council of Thailand and the National Research University Project of Thailand Office of Higher Education Commission.

\section{References}

[1] A. Kristian L., "Performance of Two Graphite Electrode Qualities in EDM of Seal Slots in a Jet Engine Turbine Vane", Journal of Materials Processing Technology, 2004, pp.152-156.

[2] A. Bergaley," Optimization of Electrical and Non Electrical Factors in EDM for Machining Die Steel Using Copper Electrode by Adopting Taguchi Technique" International Journal of Innovative Technology and Exploring Engineering (IJITEE), Vol.3, Issue 3, August ,2013, pp.44-48.

[3] Lajis, Mohd Amri, Mohd Radzi, H.C.D., Nurul Amin, A.K.M., "The Implementation of Taguchi Method on EDM Process of Tungsten Carbide", European Journal of Scientific Research 36(4), 2009, pp.609-617.

[4] V.J Nadpara, A. Choudhary, Optimization of EDM Process Parameters Using Taguchi Method with Graphite Electrode, International Journal of Engineering Trends and Technology (IJETT) - Vol.7 (2) Jan 2014, pp 48-51. https://doi.org/10.14445/22315381/IJETT-V7P239 
[5] S. Backer, C. Mathew, K. Sunny, George, "Optimization of MRR and EWR on EDM by Using Taguchi's Method and ANOVA", International Journal of Innovative Research in Advanced Engineering (IJIRAE), Vol.1 (8)September 2014, pp.106-112.

[6] T.Rajmohan and R. Prabhu, "Optimization of Machining Parameters in Electrical Discharge Machining (EDM) of 304 Stainless Steel”, Procedia Engineering 38 (2012), pp.1030-1036.

https://doi.org/10.1016/j.proeng.2012.06.129

[7] I.Puertas, and C.J Lusis, "A study on the machining parameters optimization of electrical discharge machining", Journal of materials processing technology, 2003, pp.521-526.

https://doi.org/10.1016/S0924-0136(03)00392-3

[8] S. B. Chikalthankar, V.Nandedkar, and M., Borde et.,al., "Experimental Investigations of EDM Parameters", International Journal of Engineering Research and Development 7(5), 2013, pp.31-34.

[9] Poco Graphite, Inc. Property of Graphite grades EDM-3. Available: http://poco.com

[10] I. Puertas and C.J. Luis, "Analysis of the influence of EDM parameters on Surface quality, MRR and EW of W-Co", Journal of materials Processing Technology 153-154, 2004, pp. 1026-1032.

https://doi.org/10.1016/j.jmatprotec.2004.04.346

[11] V. Senthilkumar, "Effect of Titanium Carbide particle addiction in the aluminium composite on EDM process parameters" Journal of Manufacturing Processes ,13,2011, pp. 60-66.

https://doi.org/10.1016/j.jmapro.2010.10.005 